\title{
Robust Electronic Differential Controller for an Electric Vehicle
}

\author{
A. Ravi and Sankaran Palani \\ Department of Electrical and Electronics Engineering, \\ Sudharsan Engineering College, Sathiyamangalam,Tamilnadu, India
}

Received 2013-06-24, Revised 2013-09-05; Accepted 2013-09-10

\begin{abstract}
This study presents an efficient and robust control scheme of electronic differential system for an electric vehicle. The proposed system consists of two Brushless DC motors (BLDC) that ensure the drive of the two back driving wheels of an electric vehicle. Electronic Differential Controller (EDC) ensures the maximum torque and it can control both the driving wheel independently to turn at different speeds in any curve and also distribute the power to each motor according to the steering angle. EDC is designed to facilitate experimentation with an electric vehicle using the PIC 16F877A. The BLDC motor has been controlled by the method of back EMF zero crossing detection. The effectiveness and substantiation of the proposed methods are ascertained in the MATLAB/Simulink environment and also experimentally validated. The experimental results give satisfactory performance with the proposed electronic control scheme which also ensures the stability of the vehicle in all road conditions.
\end{abstract}

Keywords: Back EMF Zero Crossing Detection, BLDC, Electric Vehicle, Electronic Differential, Steering Angle

\section{INTRODUCTION}

Environmental and economical issues are the major driving forces in the development cf Electric Vehicles (EVs). The selection of the right electric motor is the primary importance to the EVs. Several types of electric motors have been used in the past for EV applications. However from efficiency point of view, BLDC motor drives are the best choice for EV (Tashakori et al., 2010). BLDC motor has many advantages over brushed dc motors and induction motors in that, it has simple structure, high dynamic response, higher speed range, large starting torque and noiseless operation (Yang et al., 2009). In particular, the BLDC motor of the hub type is used in this study to avoid mechanical transmission losses. The usual configuration of electric vehicle presents only one traction motor driving two wheels with a mechanical differential gear. However, the overall mass of an electric vehicle is considerably increased by the mass of its accessories. Many attempts have been made to reduce electric vehicle body mass. Due to the improvement of both motor design and control technology, the conventional heavy gear box can be replaced by an Electronic Differential (ED) system. The $\mathrm{ED}$ is characterized by some features in that there is no mechanical link between the two drive wheels, the traction power is separately applied to each wheel by the controller and speed controller will apply less power to the inner wheel in the turning curves (Zhoa et al., 2009; Perez-Pinal et al., 2009).

ED based electric vehicles have many advantages over classical EV with a central motor. Indeed, mounting the motors directly to the wheels simplifies the mechanical layout and improves the overall reliability and efficiency. However one of the main issues in the design of these EVs is to ensure vehicle stability while cornering and under slippery road conditions (Nam et al., 2012; Hartani et al., 2010).

An ED is developed for EV with two separate induction motor drive based wheels. It uses direct torque control and an adaptive flux speed observer based algorithms (Tabbache et al., 2011). Fuzzy logic control based induction traction with ED gives not only good steady state response, but with no overshoot (Nasri et al., 2010).

Corresponding Author: A. Ravi, Department of Electrical and Electronics Engineering, Sudharsan Engineering College, Sathiyamangalam, Tamilnadu, India 
A traction system consists of two permanent magnet synchronous machines with ED and direct torque control has been proposed and analyzed in various conditions like vehicle driven on straight road, with slope and over a road curved left and right (Hartani et al., 2010). Hybrid Fuzzy-Sliding mode control based propulsion system consists of two induction motors with ED system to ensure the robust control of the vehicle behavior on the road (Nasri et al., 2009).

BLDC motors with their Electromagnetic Force (EMF) requires six discrete rotor position information for the inverter operation. These are generated by Halleffect sensors placed within the motor. However it is a well known fact that these sensors have a number of drawbacks. So, sensorless control is the only viable option to operate the motor for applications in harsh environments. Thus many of the drawbacks can be eliminated or reduced with position sensorless operation based on the back EMF of the motor. This study presents an electronic differential system for $\mathrm{EV}$ and also proposes the position sensorless BLDC drive based on the detection of back emf zero crossing from the terminal voltages. This method does not involve integrations. Further, by applying line to line voltages, the requirement of neutral potential has been eliminated.

\subsection{Electronic Differential}

The electronic differential is to replace the mechanical differential, which provides the required torque for each driving wheel and allows different wheel speeds. When cornering, the inner and outer wheels rotate at different speeds, because the inner wheels describe a small turning radius. The electronic differential uses the steering wheel command signal to control the power to each wheel.

Figure 1 shows the vehicle structure describing a curve, where $L$ represents the wheel base, $\delta$ the steering angle, $d$ the distance between the wheels of the same axle and $\omega_{3}$ and $\omega_{4}$ the angular speed of the wheel drives, respectively.

The linear speed of each wheel drive is expressed as a function of the vehicle speed and the radius of curve, in Equation (1) and (2) which are given below:

$$
\begin{aligned}
& \mathrm{V}_{3}=\omega_{\mathrm{r}}\left(\mathrm{R}+\mathrm{d}_{/ 2}\right) \\
& \mathrm{V}_{4}=\omega_{\mathrm{r}}\left(\mathrm{R}+\mathrm{d}_{/ 2}\right)
\end{aligned}
$$

The radius of curve depends on the wheel base and steering angle:

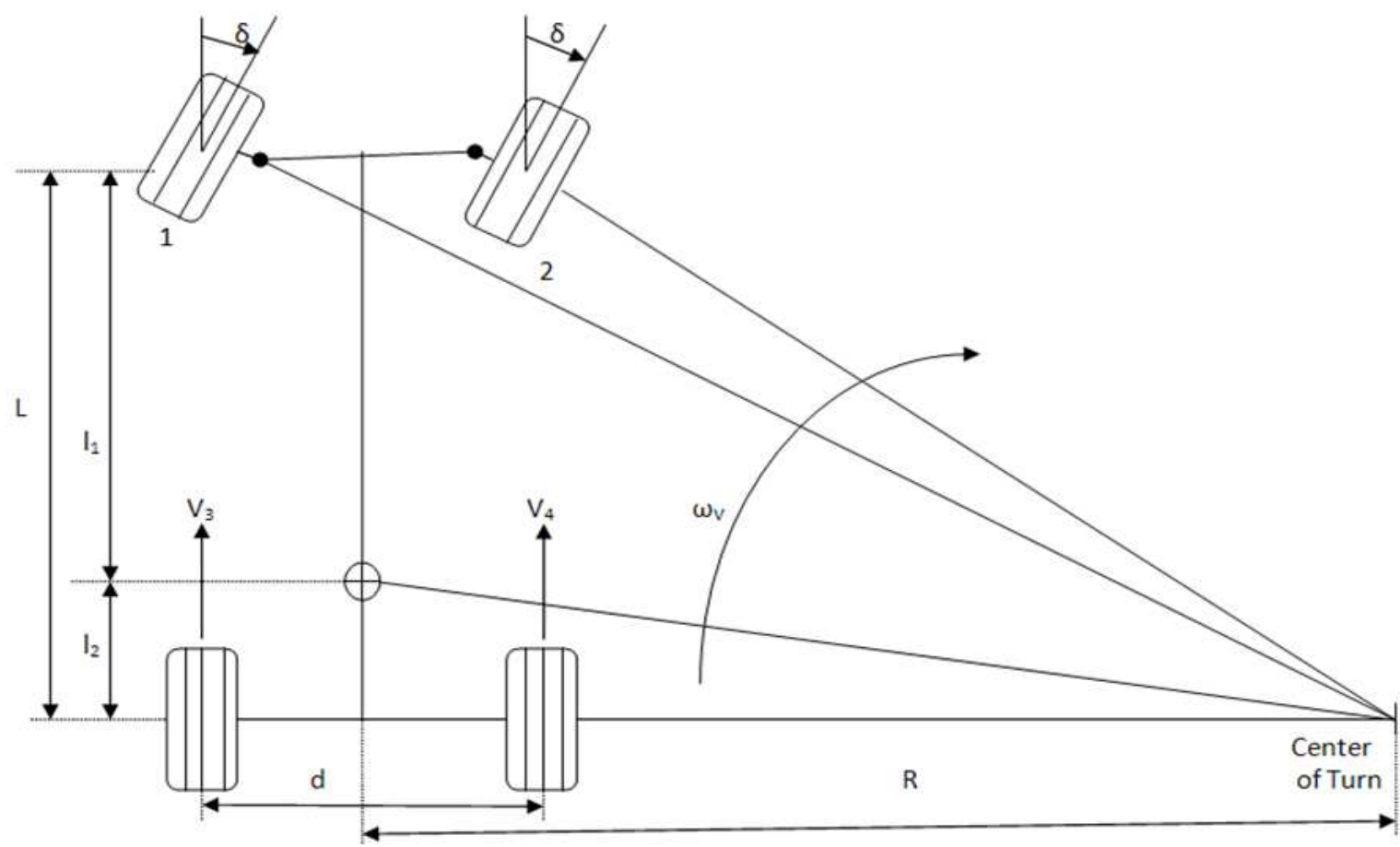

Fig. 1. Vehicle structure 


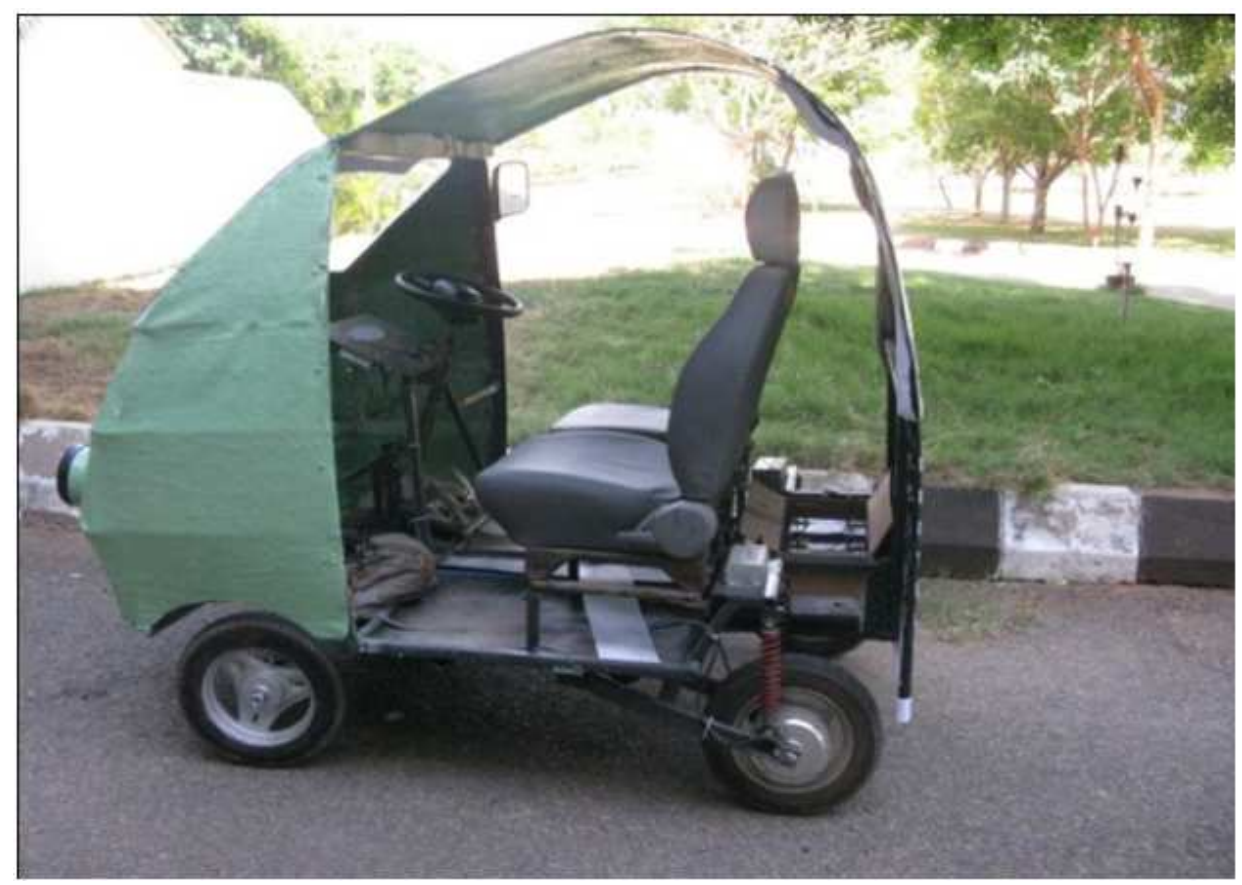

Fig. 2. Experimental in-wheel-motor-driven EV

$$
\mathrm{R}=\frac{\mathrm{L}}{\tan \delta}
$$

Substituting Equation (3) in Equation (1) and (2), we obtain the angular speed of each wheel drive as Equation (4 and 5):

$$
\begin{aligned}
& \omega_{3}=\frac{\mathrm{L}+\mathrm{d}_{/ 2} \tan \delta}{\mathrm{L}} \omega_{\mathrm{r}} \\
& \omega_{4}=\frac{\mathrm{L}-\mathrm{d}_{/ 2} \tan \delta}{\mathrm{L}} \omega_{\mathrm{r}}
\end{aligned}
$$

The difference between the angular speeds of the wheel drive is expressed by the Equation (6) as:

$$
\Delta \omega=\omega_{3}-\omega_{4}=\frac{\mathrm{d} \tan \delta}{\mathrm{L}} \omega_{\mathrm{r}}
$$

The signal of the steering angle indicates the curve direction as:

$$
\begin{aligned}
& \delta>0 \Rightarrow \text { turn right } \\
& \delta=0 \Rightarrow \text { straight ahead } \\
& \delta<0 \Rightarrow \text { turn left }
\end{aligned}
$$

\subsection{Experimental Investigations}

\subsubsection{Experimental Set Up}

An electric vehicle as shown in Fig. 2, was developed in order to implement and verify the proposed Electronic Differential Controller (EDC). In wheel BLDC motors are mounted on the hub of each wheel. Therefore we can control the torque of each wheels completely and independently. Figure $\mathbf{3}$ shows that Electronic differential controller which carries out some basic tasks that means read the calibrated steering angle potentiometer voltage and based on this it then calculates the steering angle and also determines whether the vehicle is moving straight, turning left or right then reads the throttle potentiometer voltage so that the desired vehicle speed is known.

The used BLDC hub motor and battery bank ratings are given in Table 1.

Specific experimental tests on a PIC Microcontroller (PIC 16F877A) are carried out to demonstrate the feasibility and the effectiveness of the proposed EDC in terms of robustness and stability. An experimental EV is equipped with a measuring system which is based on ARM Processor. 


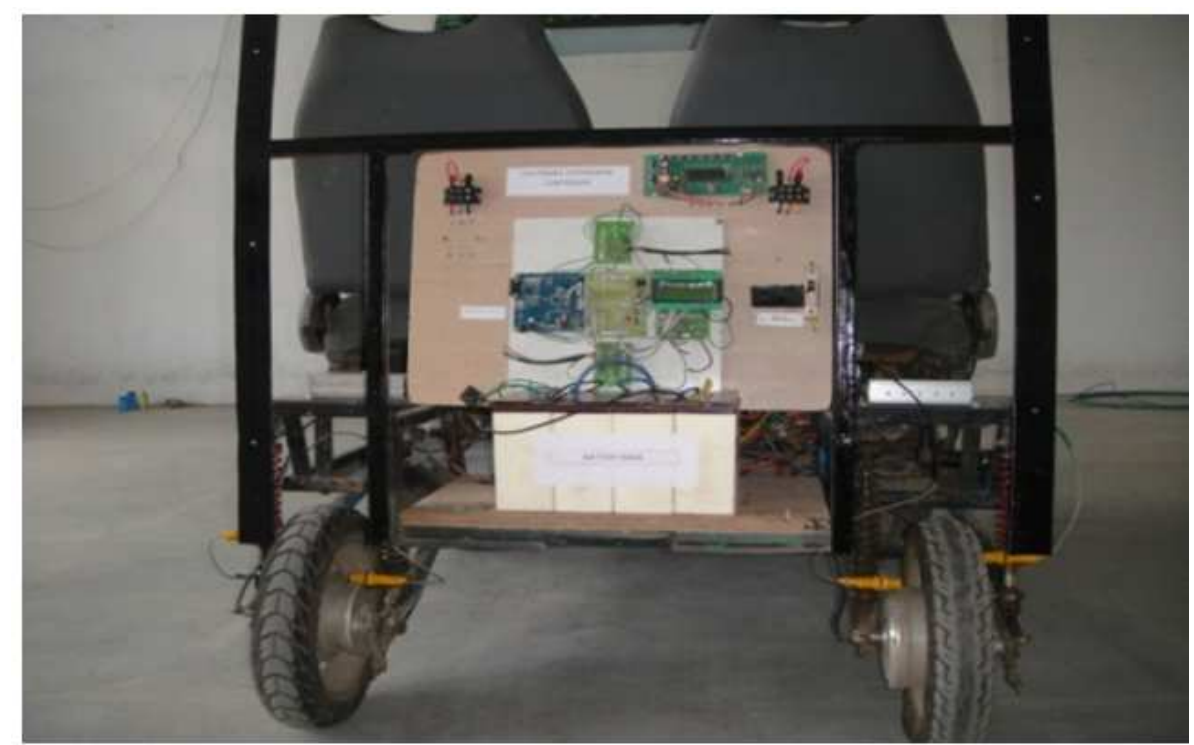

Fig. 3. Hardware implementation of electronic differential controller

Table 1. BLDC Motor and Battery bank ratings

\section{BLDC motor}

Nominal voltage $=48 \mathrm{~V}$

Max Current $=25 \mathrm{~A}$

Torque $=2.1 \mathrm{~N}-\mathrm{m}$

Output Power $660 \mathrm{~W}$

Mass $=4.8 \mathrm{Kg}$

Battery Bank

Nominal Voltage $=12 \mathrm{~V}$

Capacity $=25 \mathrm{Ah}$
Rated Current $=22 \mathrm{~A}$,

Rated Speed $=6000 \mathrm{rpm}$

Peak Torque $=6.3 \mathrm{~N}-\mathrm{m}$

Rotor Inertia $=1850$ g-sq.cm

No.of battery used $=4$

Filled weight $=6.9 \mathrm{~kg}$

(for one battery)

\subsection{Measurement Principle is as Follows}

Steering sensor voltage is 0 to $5 \mathrm{~V}$. It is assumed that:

- When the sensor voltage is $2.5 \mathrm{~V}$, steering angle is 0 which is equivalent to $60 \mathrm{deg}$. In this condition, the vehicle should move in straight path

- When the sensor voltage is less than $2.5 \mathrm{~V}$, steering angle is less than 0 which is equivalent to less than $60 \mathrm{deg}$ and the vehicle should turn left. Under this condition, left side motor speed is lower than the right side motor

- When the sensor voltage is greater than $2.5 \mathrm{~V}$, steering angle is greater than 0 which is equivalent to greater than $60 \mathrm{deg}$ and the vehicle should turn right. Under this condition, right side motor speed is lower than the left side motor

\subsection{Experimental Results}

The proposed Electronic Differential Controller (EDC) was evaluated through the following situations:

- The straightway regime, where the two motors operate at same speed

- The turning way regime where each motor operates at different speed

\subsection{Case 1: Straight Way Regime $\left(30 \mathrm{~km} \mathrm{hr}^{-1}\right)$}

When the steering angle is equal to zero, the electric vehicle drives on a straight way at a speed of $30 \mathrm{Km} \mathrm{hr}^{-1}$ and the potentiometer voltage is $2.5 \mathrm{~V}$. Under this condition, both left and right wheels speed stay always the same, is shown in Fig. 4a and b. It is also shows that pulses generated from the optical coder, then the speed is calculated based on the number of pulses per second.

\subsection{Case (ii) Curved Way Regime (40 Km hr${ }^{-1}$ )}

When the steering angle is less than zero and then the potentiometer voltage is less than $2.5 \mathrm{~V}$, the vehicle is driving as a curved road on the left side with $40 \mathrm{~km}$ $\mathrm{hr}^{-1}$ speed. In this case the driving wheels follow different paths and they turn in the same direction but with different speeds. The EDC acts on the two motor speeds by decreasing the speed of $1000 \mathrm{rpm}$ on the left side driving wheel which is situated inside the curve and on the other hand by increasing the speed of $1800 \mathrm{rpm}$ on the right side driving wheel which is situated external side of the curve as shown in Fig. $4 \mathbf{c}$ and $\mathbf{d}$. 
A. Ravi and Sankaran Palani / American Journal of Applied Sciences 10 (11): 1356-1362, 2013

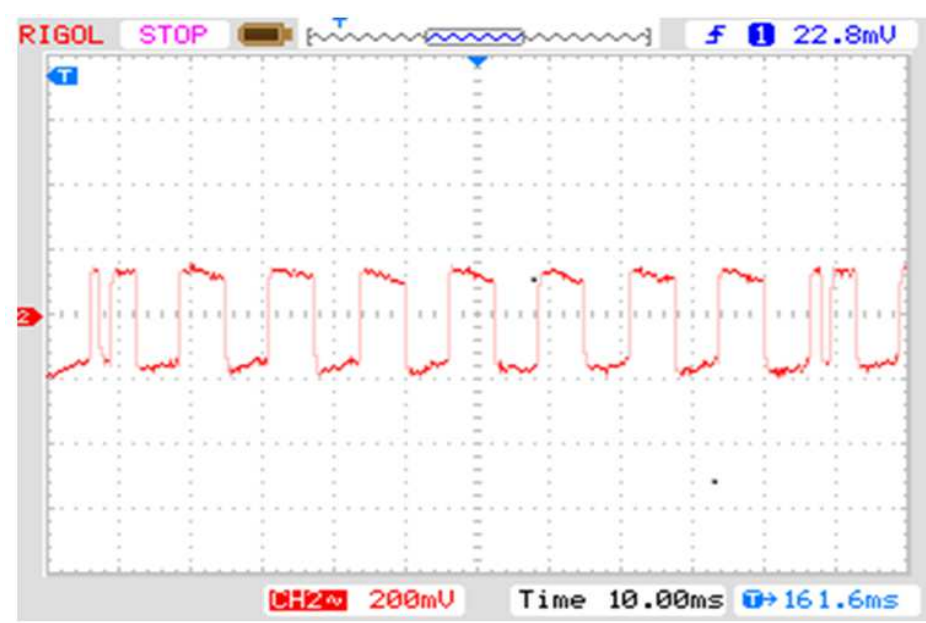

(a)

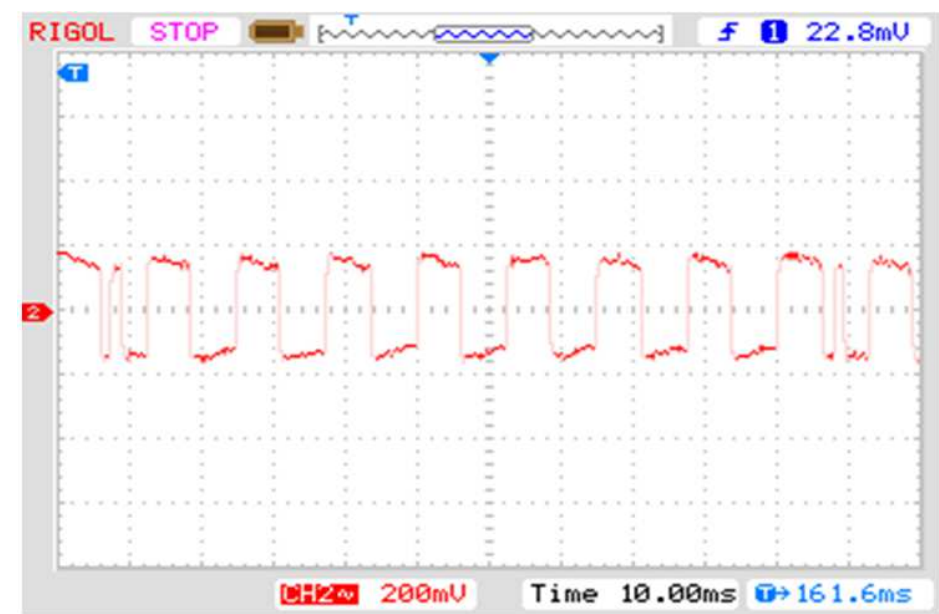

(b)

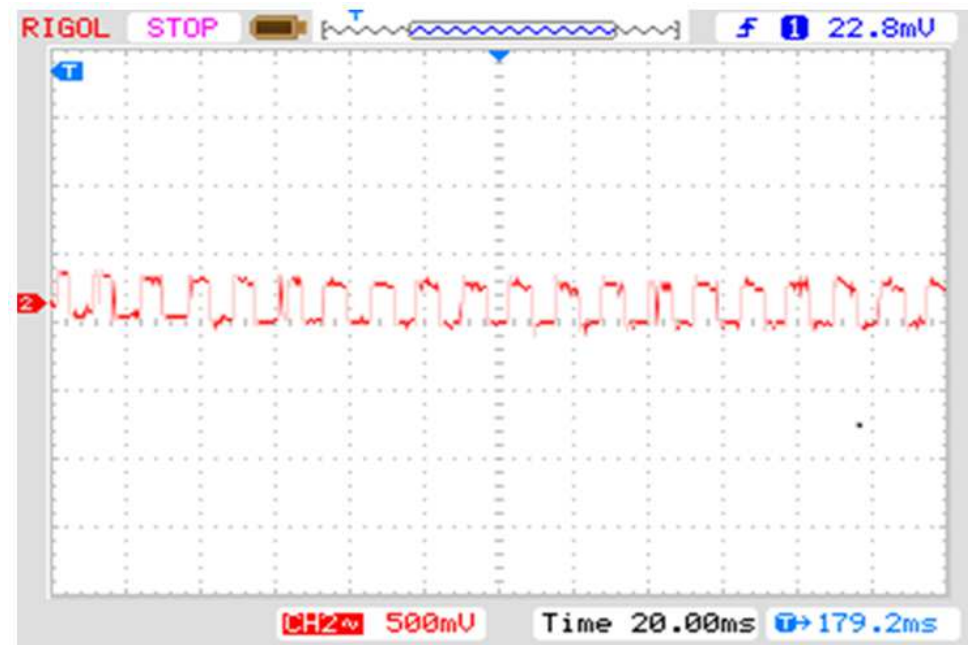

(c) 


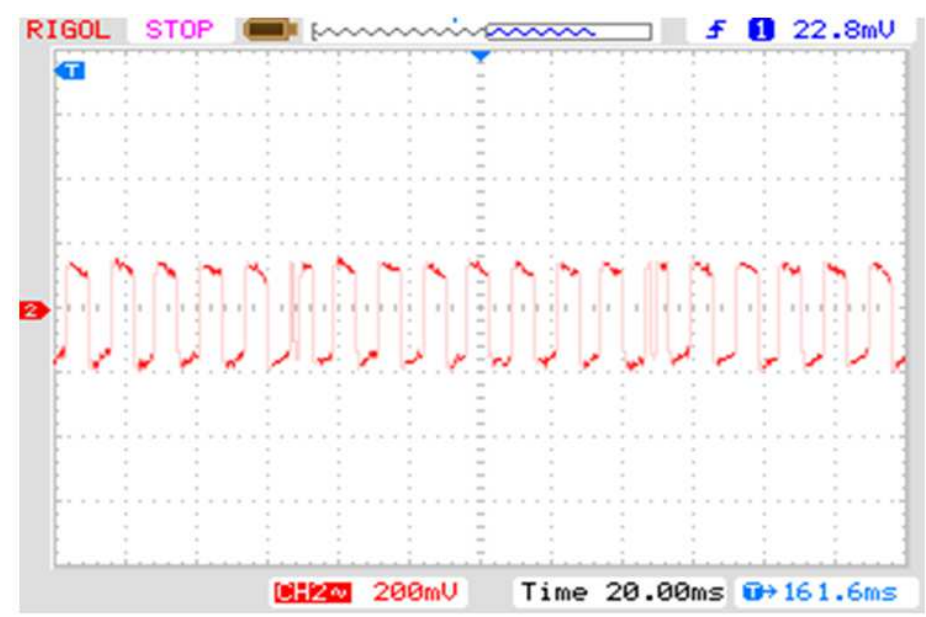

(d)

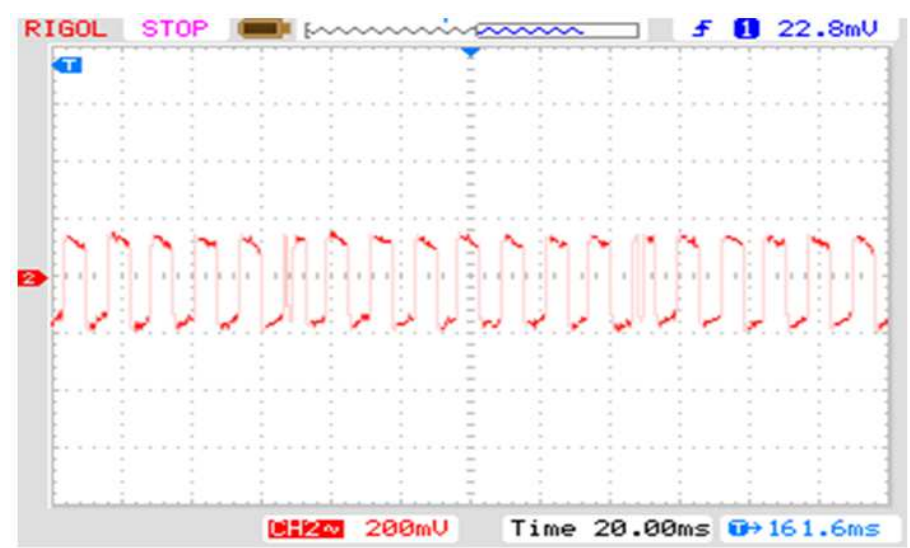

(e)

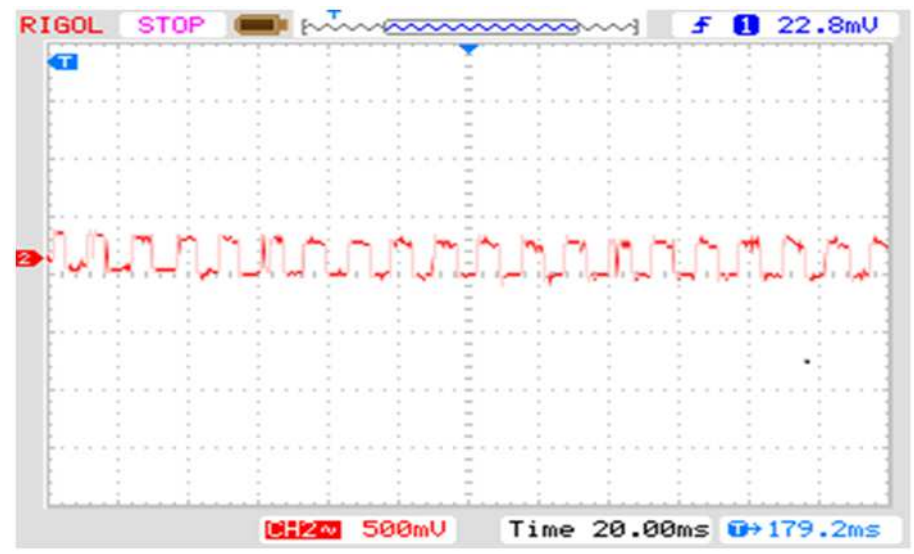

(f)

Fig. 4. (a) speed of the left side motor at $1200 \mathrm{rpm}$ when the steering angle is zero; (b) Speed of the right side motor at $1200 \mathrm{rpm}$ when the steering angle is zero; (c) speed of left side motor at $1000 \mathrm{rpm}$ when the steering angle is less than zero; (d). Speed of right side motor at $1800 \mathrm{rpm}$ when the steering angle is less than zero; (e) Speed of left side motor at $1800 \mathrm{rpm}$ when the steering angle is greater than zero; (f) Speed of right side motor at $1000 \mathrm{rpm}$ when the steering angle is greater than zero 
When the steering angle is greater than zero and then the potentiometer voltage is greater than $2.5 \mathrm{~V}$, the vehicle is driving on a curved road on the right side with $40 \mathrm{Km} \mathrm{hr}^{-1}$ speed. The EDC acts on the two motor speeds by increasing the speed of $1800 \mathrm{rpm}$ on the left side driving wheel which is situated external side of the curve and on the other hand by decreasing the speed of 1000 rpm on the right side driving wheel which is situated internal side of the curve as shown in Fig. $4 e$ and $f$.

\section{CONCLUSION}

This research paper has dealt with an electronic differential based EV. The EV drive system uses two separate BLDC motor drive based wheels. The ED reduces the drive line components and improves the overall reliability and efficiency since mechanical and gear reduction are not used. To validate the theoretical and simulation results, specific experimental tests on a PIC microcontroller (PIC 16F877A) are carried out to demonstrate the feasibility and the effectiveness of the proposed EDC in terms of robustness and stability. The performance of the proposed ED has been investigated and excellent results have been obtained under various environmental conditions which also ensure the vehicle stability while cornering and moving in slippery road condition.

\section{REFERENCES}

Hartani, K., Y. Miloud and A. Miloudi, 2010. Electric vehicle stability with rear electronic differential traction. Proceedings of the International Symposium on Environment Friendly Energies in Electrical Applications, Nov. 2-4, Ghardaïa, Algeria, pp: 1-5.

Nam, K., H. Fujimoto and Y. Hori, 2012. Lateral stability control of in-wheel-motor-driven electric vehicles based on sideslip angle estimation using lateral tire force sensors. IEEE Trans. Veh. Technol., 61: 1972-1985. DOI: 10.1109/TVT.2012.2191627
Nasri, A., A. Hazzab, I.K. Bousserhane, S. Hadjeri and P. Sicard, 2010. Fuzzy logic speed control stability improvement of lightweight electric vehicle drive. J. Electr. Eng. Technol., 5: 129-139.

Nasri, A., A. Hazzab, I.K. Bousserhane, S. Hadjeri and P. Sicard, 2009. Fuzzy-sliding mode speed control for two wheels electric vehicle drive. Int. J. Electr. Eng. Technol., 4: 499-509.

Perez-Pinal, F.J., I. Cervantes and A. Emadi, 2009. Stability of an electric differential for traction applications. IEEE Trans. Veh. Technol., 58: 32243233. DOI: 10.1109/TVT.2009.2013473

Tashakori, A., M. Ektesabi and N. Hosseinzadeh, 2010. Characteristic of suitabledrive train for electric vehicle. Proceedings of the 3rd International Conference on Power Electronic and Intelligent Transportation System, Nov. 20-21, Shenzhen, China, pp: 1-6.

Tabbache, B., A. Kheloui and M.E.H. Benbouzid, 2011. An adaptive electric differential for electric vehicles motion stabilization. IEEE Trans. Veh. Technol., 60: 104-110. DOI: 10.1109/TVT.2010.2090949

Yang, M.J., H.L. Jhou, B.Y. Ma and K.K. Shyu, 2009. A cost-effective method of electric brake with energy regeneration for electric vehicles. IEEE Trans. Ind. Electr., 56: 2203-2212. DOI: 10.1109/TIE.2009.2015356

Zhoa, Y.E., J.W. Zhang and X.Q. Guan, 2009. Modeling and simulation of electronic differential system for an electric vehicle with two-motor-wheel drive. Proceedings of the IEEE Intelligent Vehicles Symposium, Jun. 3-5, IEEE Xplore Press, Xi'an, pp: 1209-1214. DOI: 10.1109/IVS.2009.5164454 